\title{
Effects of barley and triticale silage based diets and residual feed intake on performance, profitability, and predicted $\mathrm{CO2e}$ emission of backgrounding steers
}

Mohammad Khakbazan ( $\sim$ mohammad.khakbazan@agr.gc.ca )

Agriculture and Agri-Food Canada https://orcid.org/0000-0002-0782-3443

Hushton C. Block

Agriculture and Agri-Food Canada

John Huang

Agriculture and Agri-Food Canada

Jeff J. Colyn

Agriculture and Agri-Food Canada

Vern S. Baron

Agriculture and Agri-Food Canada

John A. Basarab

University of Alberta

Changxi Li

Agriculture and Agri-Food Canada

Chinyere Ekine-Dzivenu

University of Alberta

Research

Keywords: cattle performance, net revenue, risk analysis

Posted Date: July 7th, 2021

DOI: https://doi.org/10.21203/rs.3.rs-671369/v1

License: (c) (i) This work is licensed under a Creative Commons Attribution 4.0 International License. Read Full License 


\section{Abstract \\ Background}

Feed costs are the largest expense in commercial beef production. Increasing cattle (Bos taurus) feed efficiency should reduce feed costs and increase beef profitability. This study used data from two years of a backgrounding trial conducted in Lacombe, Alberta, Canada. The evaluation looked at economic and predicted $\mathrm{CH}_{4}$ emission impacts of diet quality and cattle efficiency type in backgrounding systems. The hypothesis was that diet quality from use of barley (Hordeum vulgare c.v. Canmore) or triticale ( $x$ Triticosecale c.v. Bunker) silage-based diets and cattle efficiency type would interact to affect profitability and $\mathrm{CH}_{4}$ emissions.

\section{Results}

The experimental design was a four (cattle efficiency type; defined by residual feed intake (RFI)) by two (barley or triticale silage-based rations) factorial treatment with two replicates (pen of eight steers)/treatment/year over two years. Year was a random blocking factor. Cattle weight, intake, and diet composition data were combined with market prices to assess profitability. Methane emissions data were predicted from observed performance using a nutrient requirement model. Effects of diet and cattle efficiency type on profitability and $\mathrm{CO}_{2}$ e emissions were assessed using statistical and stochastic risk simulation. By supporting greater gain and feed efficiency, the barley silage diet provided higher net revenue (NR) and lower $\mathrm{CO}_{2}$ e emission ( $\mathrm{P}<0.01$ for both). The NR was affected by observed pen average RFI. Risk simulation showed preference for efficient steers and use of barley silage-based diets.

\section{Conclusions}

The profitability of beef backgrounding was affected by cattle efficiency type and diet quality with higher quality diets also lowering $\mathrm{CO}_{2}$ e emission and little evidence of interaction between cattle efficiency type and diet quality. The difference in certainty equivalent ( $\$ 30 /$ steer) of efficient steers on barley silage and inefficient steers on barley silage or efficient or inefficient steers on triticale silage supports a beef backgrounding producer focus on diet quality and cattle efficiency type. However, inefficient steers on barley silage still generated higher certainty equivalent per steer than efficient or inefficient steers on triticale silage. This study did not address potential agronomic differences, including yield, which could provide nuance to forage choice.

\section{Background}

Feed costs is the single largest expense in most commercial beef production [1, 2] and feeding and management through the winter comprise up to two-thirds of the total cost of primary beef production in Canada [3]. Increasing cattle feed efficiency should increase the profitability and economic sustainability of beef production.

There is individual animal variation in feed efficiency. Residual feed intake (RFI) [4], is the difference between actual feed intake and expected intake given observed weight and gain [5]. It is a measure of feed efficiency that is independent of body size, production, and growth traits [6,7]. This increases its utility for comparisons across production levels and production phases for the selection of more efficient cattle types [7, 8]. The moderate repeatability [5] and moderate heritability $[7,9,10]$ of RFI should allow for the selection of more efficient cattle [11, 12].

Selection for RFI has been shown to reduce feed costs $[13,14]$ and increase economic benefits $[7,15,16]$. Selection for low RFI (efficient) cattle can also have a variety of environmental benefits, including reduced methane emissions $[7,17]$, reduced manure production [7], and smaller farm area requirements [5]. 
The measurement of individual animal intake for accurate estimation of RFI usually requires access to high-tech feeding facilities [18]. Testing for RFI is also expensive and slow to return economic benefits [7, 12]. The benefits of selecting for feed efficiency in cattle have not yet been recognized by many producers, further limiting the widespread adoption of RFI selection [19]. A survey of 269 commercial cow-calf producers in the United States found that only one-third of surveyed producers correctly identified the definition of feed efficiency, and only $15 \%$ of producers had any knowledge of residual feed intake [20]. Consequently, the measurement of cattle RFI has thus far been limited to researchers and progressive seed stock producers.

The increasing access to RFI measurement has generated interest in the use of genomic technologies to predict genomic expected progeny differences (gEPD) and breeding values [21, 22, 23, 24]. Genomic selection of RFI allows for moderately accurate selection of cattle early in life [25], providing producers with timely access to feed efficiency data that can be used for selection of efficient cattle.

The responsiveness of cattle to different quality diets is relatively well understood [26] allowing joint consideration of yield and quality with crop selection models [27]. Use of small plot cultivar comparison data with a crop variety evaluation calculator [27] identified two different crop varieties, Canmore barley and Bunker triticale, expected to differ substantially in quality, but have comparable economic value.

In addition to the independent economic and environmental benefits from improving cattle efficiency through managing nutrition and selecting for efficient cattle, there is some evidence that an interaction between cattle feed efficiency and production environment exists. Unpublished research from the Lacombe Research Centre found that low RFI beef cows gained more body fat and body weight (BW) than high RFI cows when both groups swath grazed forages under extensive Canadian winter conditions. This suggests that efficient animals are may be more adaptable and less susceptible to stress than inefficient animals [5]. The objective of this study was to evaluate the economic effects of barley or triticale silage-based diets and cattle efficiency type for backgrounding steers. Additionally, stochastic simulation, which allows cost, revenue, and production factors to be analyzed as statistical distributions rather than as point estimates [28, 29, 30, 31] was used to assess probable cattle producer preferences. Finally, performance of animals in terms of $\mathrm{CH}_{4}$ emissions (in $\mathrm{CO}_{2}$ equivalent $\left(\mathrm{CO}_{2} \mathrm{e}\right)$ ) under different diet treatments and cattle efficiency types was investigated. The hypothesis was that differences in diet quality from use of barley or triticale silage-based diets would interact with beef cattle efficiency type and affect backgrounding profitability and $\mathrm{CO}_{2} \mathrm{e}$ emissions.

\section{Materials And Methods}

\section{Experimental design}

The steers used in this two-year study were maintained at the Lacombe Research and Development Centre, Agriculture and Agri-Food Canada, Lacombe, Alberta. All dietary treatments and experimental procedures were approved by the Lacombe Research and Development Centre Animal Care Committee and animals were cared for as outlined under the guidelines established by the Canadian Council on Animal Care [32]. Calves were born between the beginning of March and mid-May in 2016 (year 1) and 2017 (year 2). The experimental design for the animal evaluation trials was a four (cattle efficiency type) by two (diet quality) factorial treatment structure with two replicates (pens of 8 steers) per treatment combination repeated over two years in a randomized complete block design. Prior to the backgrounding trials, 128 steer calves were tissue sampled for genotyping on Illumina Bovine SNP50 Beadchip and prediction of RFI. The prediction of RFI was conducted with the Genomic Best Linear Unbiased Prediction (GBLUP) method as described previously [23,33], using a Canadian beef cattle with both genotypes and RFI as a reference population $(\mathrm{N}=4583)$. Genotyping before weaning allowed sorting of calves into cattle efficiency type groups before a RFI test could be completed. In each of the two 112-day trials, which ran from October 2016 to January 2017 and November 2017 to February 2018, the calves were split into quartiles based on 50k SNP predicted RFI, stratified by weight, and randomized to pens. Within each cattle efficiency quartile (4 pens), each pen was randomized to a barley (Hordeum vulgare c.v. Canmore) silage or triticale (x Triticosecale c.v. Bunker) silage-based diet (Table 1). Both diets were approximately $75 \%$ silage and $25 \%$ corn (Zea mais) dried distillers' grains (cDDGS) on a dry matter (DM) basis. The 
cDDGS was included to address a metabolizable protein deficiency. Diets were formulated to minimize expected feed cost of gain with steers expected to approximately gain $1 \mathrm{~kg} /$ day.

Table 1

Means and standard deviation ( \pm SD) for predicted and observed residual feed intake $(\mathrm{RFI})$, and steer average daily gain (ADG) for diet treatments over the two-year study

\begin{tabular}{|llllll|}
\hline Year & Diet & Predicted RFI quartile & Predicted RFI & Observed RFI & ADG (kg/steer/day) \\
\hline 1 & Barley silage & 1 & $-0.131 \pm 0.002$ & $-0.124 \pm 0.139$ & $0.977 \pm 0.03$ \\
\hline 1 & Barley silage & 2 & $-0.024 \pm 0.002$ & $0.140 \pm 0.081$ & $0.885 \pm 0.05$ \\
\hline 1 & Barley silage & 3 & $0.065 \pm 0.002$ & $-0.024 \pm 0.019$ & $0.876 \pm 0.11$ \\
\hline 1 & Barley silage & 4 & $0.158 \pm 0.001$ & $0.008 \pm 0.408$ & $0.821 \pm 0.02$ \\
\hline 1 & Triticale silage & 1 & $-0.133 \pm 0.002$ & $-0.051 \pm 0.438$ & $0.803 \pm 0.02$ \\
\hline 1 & Triticale silage & 2 & $-0.024 \pm 0.000$ & $-0.075 \pm 0.060$ & $0.869 \pm 0.08$ \\
\hline 1 & Triticale silage & 3 & $0.068 \pm 0.008$ & $0.249 \pm 0.006$ & $0.921 \pm 0.01$ \\
\hline 2 & Triticale silage & 4 & $0.160 \pm 0.005$ & $-0.123 \pm 0.022$ & $0.858 \pm 0.09$ \\
\hline 2 & Barley silage & 1 & $-0.115 \pm 0.003$ & $0.140 \pm 0.472$ & $1.081 \pm 0.01$ \\
\hline 2 & Barley silage & 2 & $-0.019 \pm 0.000$ & $-0.011 \pm 0.209$ & $1.039 \pm 0.03$ \\
\hline 2 & Barley silage & 4 & $0.055 \pm 0.000$ & $0.144 \pm 0.484$ & $1.017 \pm 0.09$ \\
\hline 2 & Triticale silage & 1 & $0.137 \pm 0.001$ & $-0.273 \pm 0.148$ & $1.037 \pm 0.10$ \\
\hline 2 & Triticale silage & 2 & $-0.117 \pm 0.008$ & $0.135 \pm 0.341$ & $0.868 \pm 0.08$ \\
\hline 2 & Triticale silage & 3 & $-0.020 \pm 0.001$ & $-0.124 \pm 0.173$ & $0.941 \pm 0.04$ \\
\hline 2 & Triticale silage & 4 & $0.053 \pm 0.001$ & $-0.129 \pm 0.163$ & $0.980 \pm 0.08$ \\
\hline & & $0.141 \pm 0.006$ & $0.118 \pm 0.498$ & $0.832 \pm 0.02$ \\
\hline
\end{tabular}

Animal performance data, including daily feed intake, monthly BW, and ultrasound backfat thickness measures, were collected throughout the study. Steers were weighed in the morning before feeding on 2 consecutive days at the start and end of trial, and at 28-day intervals during the trials. Ultrasound backfat thickness $(\mathrm{mm})$ used an Aloka 500V diagnostic real-time ultrasound with a 17-cm 3.5 MHz linear array transducer (Overseas Monitor Corporation Ltd., Richmond, BC) with procedures as described by Brethour [34].

Dry matter intake (kg/steer/day) was calculated from daily feed mixing and pen delivery records and weekly ingredient DM content. Weekly feed samples were composited monthly and analysed to determine diet energy content. Feeding targeted ad libitum intake with slick bunk management to minimize feed waste. When orts occurred, they were weighed and a sub-sample dried to allow dry matter intake (DMI) and diet energy content correction. Feed efficiency was calculated from observed average daily gain (ADG) and DMI.

\section{Economic analysis}

The revenue returns for the trial period were analyzed separately by using appropriate nine-year average (2010-2018) cattle prices at the beginning and at ending of this phase [35]. Since steers were born in March and weaned in October, the feeder cattle price series for 136-408 kg weight classes used for the price distribution of steer calf purchase was the historical monthly price of October. Comparable January and February price series for feeder cattle weight classes within the 227-454 $\mathrm{kg}$ weight range were used for the price distribution of steer sales at the end of the feeding period. Prices for appropriate steer weight category were multiplied by actual weight of steers, less a $3 \%$ shrinkage [36], to determine initial and final price on a per 
steer basis. There was no seasonality adjustment for feeder prices as historical monthly prices for the month that calves were weaned or sold at the end of trial were used. The net revenue (NR) function (beef returns - variable costs) per steer for the different beef management treatments is expressed as follows:

$\left.N R=\left[P_{E}\left(W_{F}+A D G * D a y\right)\right]-\left[P_{F} * W_{F}\right)+\left(P_{B} * W_{B}\right)+\left(P_{T} * W_{T}\right)+V C\right]$

where $P_{E}$ is the price of steer at the end of trial; $W_{F}$ is the beginning weight of feeder; $A D G$ is the average daily gain; Day is the number of days spent on feed; $P_{F}$ is the price of feeder steer at the beginning of trial; $P_{B}$ is the price of barley silage-based diet; $\mathrm{P}_{\mathrm{T}}$ is the price of triticale silage; $\mathrm{W}_{\mathrm{B}}$ is the weight of barley silage consumed; $\mathrm{W}_{\mathrm{T}}$ is the weight of triticale consumed, and $\mathrm{VC}$ is the variable cost. The NR was expressed in CAD \$/steer. Barley and triticale silage price discovery was a challenge as these ingredients are rarely traded. To address this challenge, the analysis was done under two scenarios: $A$ ) the value for both the barley and triticale silages were estimated based on an industry standard practice of using barley bushel price multiplied by 12.5 for a standard silage of 35\% DM (\$56.6/tonne) [37] and then adjusted for the actual DM of the silages used in the study

[35]. B) The value of barley and triticale silages were based on back calculation from known cattle prices and other input costs. Assuming all other prices and costs are known except the cost of silage, a breakeven point $(\mathrm{NR}=0)$ was calculated and considered to represent the value of barley or triticale silages.

\section{$\mathrm{CH}_{4}$ emission estimates}

The $\mathrm{CH}_{4}$ emissions estimates for backgrounding steers were the median estimates obtained from the Nutrient Requirements of Beef Cattle model (NASEM) [26]. The intake and weighted diet composition observed for each pen of steers was entered into the model along with observed steer weights and body condition. The net energy for maintenance adjuster within the model was then used to get predicted $A D G$ to equal observed $A D G$. The $\mathrm{CH}_{4}$ emissions were the median of the model estimates. The discrepancy between observed and model predicted intake was noted and used in an additional simulation.

The NASEM [26] was also used to estimate steer performance under the hypothetical scenario of steers receiving a silage only (i.e. no cDDGS-based supplement) diet. This scenario used the observed weighted average silage composition as the sole feed ingredient. Intake was based on model predicted intake with the same per cent adjustment as the discrepancy between observed and predicted intake noted previously for observed steer performance. The metabolizable energy limited gain was used to revise modeled steer final weight. Adjustments were iterative for each pen until predictions stabilized and expected intake, $A D G$, and methane emissions were recorded.

The $\mathrm{CH}_{4}$ emissions were converted to $\mathrm{CO}_{2}$ e by multiplying by 25 [38] and expressed on a per steer per day, a per $\mathrm{kg}$ of DMI, a per $\mathrm{kg}$ of $\mathrm{ADG}$, and a net revenue per $\mathrm{kg}$ of $\mathrm{CO}_{2} \mathrm{e}$.

\section{Statistical analysis}

Observed pen average RFI was determined as the difference between DMI predicted from regression observed DMI on year, diet type, metabolic BW (BW $\left.{ }^{0.75}\right), A D G$, and final ultrasound backfat and observed DMI, as per Basarab et al. [16], except that regression used pen averages instead of individual animal data. Observed, and predicted, intakes were standardized to $10 \mathrm{MJ}$ $\mathrm{ME} / \mathrm{kg}$ of diet DM, as appropriate for backgrounding or forage-based diets, before determination of RFI. Pen average observed RFI were determined separately for each year of the study, using all pens in each year.

The accuracy and precision of expected RFI values for pens of steers having randomized steers to pens based on genomic predicted RFI was assessed by comparing to observed pen average RFI by regression and concordance correlation coefficient determination $[39,40]$.

All response data for this study were analysed using the mixed models procedure of SAS [41, 42]. Individual pen served as the experimental unit. Each year of the study was considered a random blocking factor. The two dietary treatments (barley or triticale silage-based diet) were a categorical factor. The observed RFI for each pen were a quantitative factor. The model assessed the effect of diet, the linear and quadratic effects of RFI, and any interaction between diet and linear or quadratic RFI 
effects. An alpha of 0.05 was used for significance, and following a type I sums of squares analyses, a solution was fitted that included all relevant treatment effects and interactions. These analyses were carried out for gross cost and revenue, NR, silage breakeven value at both observed silage DM and a standardized $35 \% \mathrm{DM}$, and $\mathrm{CO}_{2}$ e for $\mathrm{CH}_{4}$ emissions as predicted from observed performance. Analyses on DMI, ADG, and feed efficiency are included for context as major determinants of costs, revenue, and profitability.

The scenarios estimating $\mathrm{CH}_{4}$ emissions with a silage-only diets were analysed for the effect of supplementation (actual silage-based diets vs. simulated silage-only diets) and silage (barley silage vs. triticale silage) as a 2 by 2 factorial using the mixed model procedure of SAS [41, 42]. Pen was treated as a sub-plot factor for comparison between actual and simulated diets and year remained a random blocking factor. Effect of RFI was disregarded due to observed impact on the same measures when considering only the actual diets, and the inability to determine an appropriate RFI for simulated scenarios.

\section{Risk analysis - Stochastic Efficiency with Respect to a Function}

Microsoft Excel add-in Simulation and Econometrics to Analyze Risk (SIMETAR), developed by Richardson et al. [43], was used to simulate feeder price at the beginning and end of trial, simulate ADG distributions, and calculate distributions of NR for steers. The multivariate empirical distributions derived from experimental ADG, was multiplied by a simulated price distribution derived from feeder historical prices (2010-2018) with SIMETAR software to calculate simulated NR for each treatment $[44,45]$. The simulated ADG was generated from the observed ADG for each of the treatments using 125 steers in 2016/2017 and 128 steers in 2017/2018. Two-sample Hotelling $T^{2}$ test was used to test for significant differences between the simulated data and the actual data [46]. The two-sample Hotelling $T^{2}$ test is a multivariate distribution test to determine if actual steer weight matrix and the simulated weight matrix or the historical feeder matrix and the simulated feeder matrix have equivalent mean vectors. We test the null hypotheses that the mean vectors are equal and could not be rejected. The $T^{2}$ test can be converted to an F statistic and significance can be tested against F-distribution with $\rho$ and $n-\rho, \rho$ is the number of variables, $n$ is the sample size, and $n-\rho$ is degree of freedom. If computed $F$ (test value) is not greater than the critical $F$ value, the null hypotheses cannot be rejected. That is, the mean vectors of steer actual and simulated weights are considered equal. SIMETAR was used to construct a cumulative probability distribution function (CDF) from simulated NR with probability ranging from 0.0 to 1.0 for barley silage-based diets vs triticale silage-based diets and efficient (observed pen average $R F I<0$ ) and inefficient (observed pen average RFI > 0) treatment combinations.

A constant relative risk-aversion function was used with stochastic efficiency with respect to a function (SERF) in this study to evaluate risk-efficient alternative treatments $[43,47,48]$. SERF identifies the most efficient alternative treatments for a range of risk preferences by ranking alternatives in terms of certainty equivalent (CE) [43]. The CE is a measure of a payoff a decision maker (in this case backgrounding cattle producer) would have to receive to be indifferent between the certain payoff and a riskier alternative [47]. For a given level of absolute risk aversion coefficient (ARAC), the CE is calculated using the negative exponential equation defined by Pratt [49] and Hardaker et al. [47] as $r_{a}(w)=-u^{\prime \prime}(w) / u^{\prime}(W)$, which represents the ratio of the second and first derivatives of the decision-maker's utility function, $u(w)$. The $r_{a}(w)$ is risk aversion coefficient and $w$ is a measure of wealth. The negative exponential utility function assumes decision makers prefer less risk to more given the same expected return and they have constant absolute risk aversion (i.e. they view a risky strategy for a specific level of risk aversion the same without regard for their level of wealth). Across two or several alternatives, a higher CE, with the same level of ARAC is considered a best management alternative. That is, the CE value that is greater than all other CE values with the same level of ARAC corresponds to a preferred alternative. The CE values were estimated for efficient steers (observed RFI less than zero) on barley silage-based diet, inefficient steers (observed RFI greater than zero) on barley silage-based diet, efficient steers (observed RFI less than zero) on triticale silage-based diet, and inefficient steers (observed RFI greater than zero) on triticale silage-based diet.

The CE values were calculated for the ARAC for an upper boundary of 4/average NR [47]. The ARAC ranged from 0 (risk neutral) to 0.005 (highly risk averse). There were 500 simulated NR values computed (data not shown). The simulated NR values were then used to determine the risk premium to evaluate the preferred strategies under risk. 


\section{Results}

\section{Adequacy of RFI predictions}

With the predicted pen average RFI values used in assigning steers to pens based on RFI quartiles having no relationship $(P=$ $0.67)$ to observed pen average $\mathrm{RFI}$, deviation $(P<0.05)$ from the isopleth, and a low concordance correlation coefficient of -0.054 due to a low precision coefficient of -0.077 , subsequent analyses are based on regression on observed pen average RFI to describe cattle efficiency type, instead of predicted RFI quartile. Pen of steers remained as the experimental unit.

\section{Economic analyses data}

The unit prices for cattle, feed, bedding, yardage, and other costs used in this economic evaluation are presented in Table 2. These prices indicate that the price of steers declines by $0.17 \%$ per $\mathrm{kg}$ increase in weight for steer calves bought in October and $0.11 \%$ per $\mathrm{kg}$ increase in weight for steers sold in January or February. This compares to a multi-year industry expected price decline range of 0.11 to $0.18 \%$ per $\mathrm{kg}$ of increased BW [35] with seasonal peaks for light steers in November and heavier steers in April. 
Table 2

Input and output prices. The average steer prices at beginning and end of trial were based on the Alberta Weekly Feeder Prices from 2010 to 2018 in CanFax.

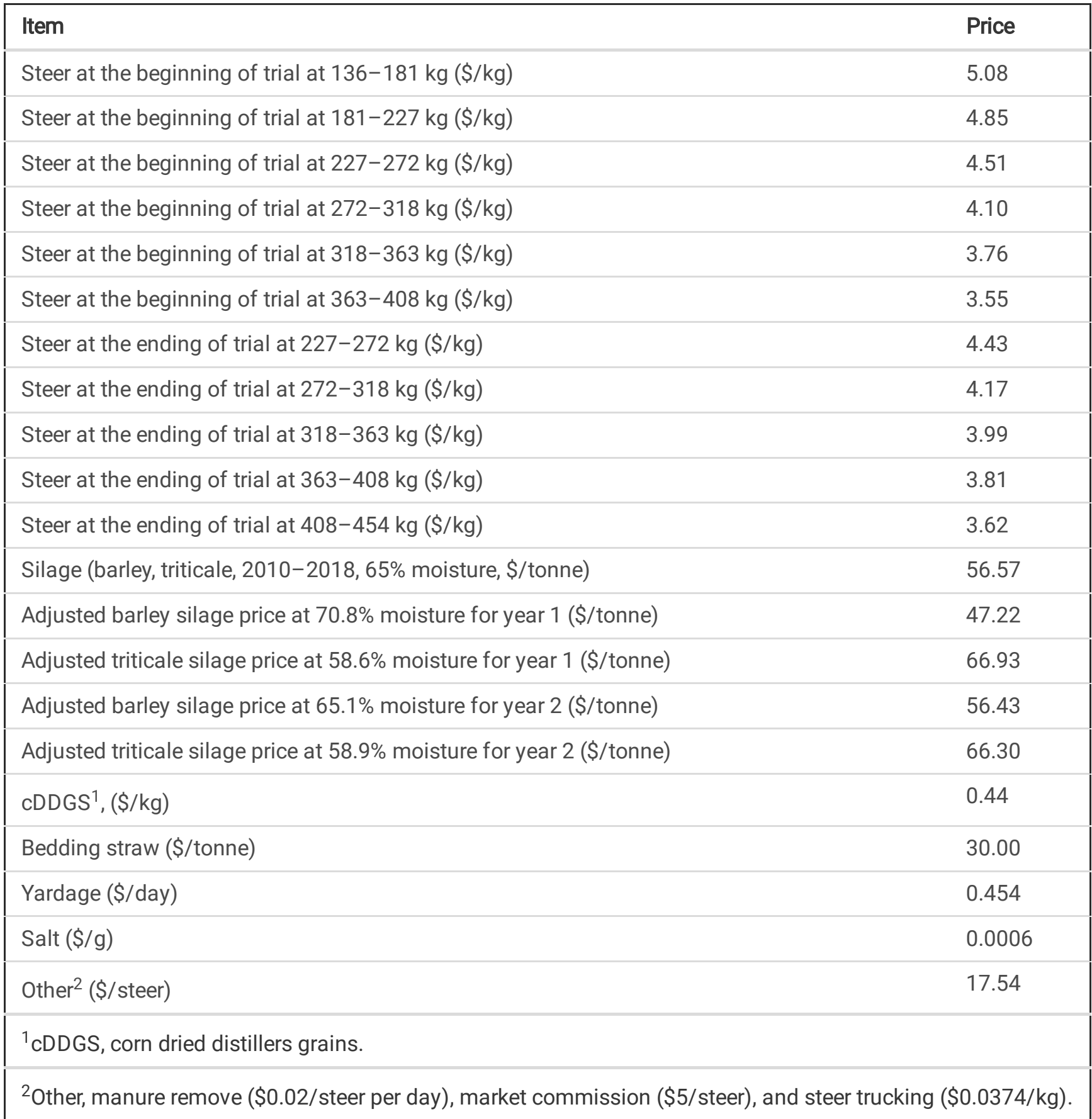

\section{Steer performance}

Average ( $\pm \mathrm{sd}$ ) on-test weight of steers over the two years was $284.2 \pm 35.9 \mathrm{~kg}$ for steers on the barley diet and $283.3 \pm 36.4 \mathrm{~kg}$ for triticale diet (data not shown). Average off-test weight of steers for the same period was $392.4 \pm 41.3 \mathrm{~kg}$ for barley diet and $382.3 \pm 39.3 \mathrm{~kg}$ for triticale diet.

Regression analysis on observed pen average RFI and diet used categorical variables for barley or triticale diets and quantitative values for the observed RFI for each pen. For DMI, there were no interactions $(P>0.05)$ between diet and the linear or quadratic effects of RFI, no independent linear or quadratic effects $(P>0.05)$ of $R F I$, and only an effect $(P<0.01)$ of diet (Table 3). The barley silage-based diet DMI, at $5.97 \mathrm{~kg} / \mathrm{steer} /$ day, was lower than the $6.42 \mathrm{~kg} / \mathrm{steer} /$ day observed for the triticale silage-based diet (Table 4). This effect of diet on DMI resulted in a difference $(P<0.01)$ in the DMI of barley and triticale silages ( $4.45 \pm 0.14$ vs. $4.77 \pm 0.30 \mathrm{~kg} / \mathrm{steer} /$ day) (data not shown). 
Table 3

P-values for Type I effects ${ }^{1}$ for diet, observed residual feed intake (RFI), and interactions of diet with RFI.

\begin{tabular}{|c|c|c|c|c|c|}
\hline Category $^{2}$ & Diet & $\mathrm{RFI}_{\text {linear }}$ & Diet $\times \mathrm{RFI}_{\text {linear }}$ & $\mathrm{RFI}_{\text {quadratic }}$ & Diet $\times \mathrm{RFI}_{\text {quadratic }}$ \\
\hline DMI, kg/steer/day & $<0.01$ & 0.31 & 0.71 & 0.37 & 0.17 \\
\hline ADG, kg/steer/day & $<0.01$ & 1.00 & 0.41 & 0.36 & 0.12 \\
\hline Feed efficiency, kg ADG:kg DMI & $<0.01$ & 0.31 & 0.25 & 0.92 & 0.58 \\
\hline Gross cost, $\$ /$ steer & $<0.01$ & 0.31 & 0.71 & 0.34 & 0.18 \\
\hline Gross revenue, \$/steer & 0.01 & 0.15 & 0.61 & 0.42 & 0.82 \\
\hline Net revenue, $\$$ /steer & $<0.01$ & 0.02 & 0.40 & 0.86 & 0.53 \\
\hline \multicolumn{6}{|l|}{ Breakeven silage value, \$/tonne } \\
\hline At actual DM & 0.14 & 0.03 & 0.36 & 0.91 & 0.87 \\
\hline At 35\% DM & $<0.01$ & 0.03 & 0.48 & 0.86 & 0.60 \\
\hline \multicolumn{6}{|l|}{ Methane emissions, $\mathrm{CO}_{2} \mathrm{e}$} \\
\hline $\mathrm{kg} /$ steer/day & $<0.01$ & 0.21 & 0.64 & 0.18 & 0.25 \\
\hline $\mathrm{kg} / \mathrm{kg} \mathrm{DMI}$ & 0.45 & 0.73 & 0.99 & 0.91 & 0.10 \\
\hline $\mathrm{kg} / \mathrm{kg} \mathrm{ADG}$ & $<0.01$ & 0.24 & 0.22 & 0.84 & 0.31 \\
\hline Net revenue, $\$ / \mathrm{kg}$ of $\mathrm{CO}_{2} \mathrm{e}$ & $<0.01$ & 0.03 & 0.49 & 0.84 & 0.60 \\
\hline \multicolumn{6}{|c|}{$\begin{array}{l}{ }^{1} \text { Fitted regression equations based on simplest model including all effects with } P<0.05 \text { and preceding effects (i.e. if diet } \\
\text { had a linear interaction with RFI, then diet and RFI linear effects would be included even if they had } P>0.05 \text { ). }\end{array}$} \\
\hline
\end{tabular}


Table 4

Fitted regression equation coefficients for effects of diet, observed residual feed intake (RFI), and interactions of diet with RFI.

\begin{tabular}{|c|c|c|c|c|c|}
\hline \multirow[b]{2}{*}{ Category ${ }^{1}$} & \multicolumn{3}{|c|}{ Diet intercept coefficients } & \multirow[t]{2}{*}{$\mathrm{RFI}_{\text {linear }}$ slope } & \multirow[t]{2}{*}{ SE } \\
\hline & Barley silage & Triticale silage & SE & & \\
\hline DMI, kg/steer/day & 5.97 & 6.42 & 0.15 & & \\
\hline ADG, kg/steer/day & 0.97 & 0.88 & 0.03 & & \\
\hline Feed efficiency, kg ADG:kg DMI & 0.16 & 0.14 & 0.0034 & & \\
\hline Gross cost, $\$ /$ steer & 263.19 & 275.61 & 4.11 & & \\
\hline Gross revenue, \$/steer & 288.13 & 268.19 & 7.13 & & \\
\hline Net revenue, $\$$ /steer & 24.95 & -7.42 & 5.90 & -30.24 & 12.01 \\
\hline \multicolumn{6}{|l|}{ Breakeven silage value, \$/tonne } \\
\hline At actual DM & 68.31 & 61.42 & 4.71 & -21.62 & 8.04 \\
\hline At $35 \%$ DM & 73.66 & 52.18 & 3.95 & -19.76 & 9.08 \\
\hline \multicolumn{6}{|l|}{ Methane emissions, $\mathrm{CO}_{2} \mathrm{e}$} \\
\hline $\mathrm{kg} /$ steer/day & 3.09 & 3.35 & 0.06 & & \\
\hline kg/kg DMI & 0.52 & 0.52 & 0.01 & & \\
\hline $\mathrm{kg} / \mathrm{kg}$ ADG & 3.23 & 3.81 & 0.08 & & \\
\hline Net revenue, $\$ / \mathrm{kg}$ of $\mathrm{CO}_{2} \mathrm{e}$ & 7.98 & -2.04 & 1.81 & -9.12 & 3.68 \\
\hline
\end{tabular}

For $A D G$, there were no interactions $(P>0.05)$ between diet and the linear or quadratic effects of $R F I$, no independent linear or quadratic effects $(P>0.05)$ of $R F I$, and only an effect $(P<0.01)$ of diet (Table 3$)$. Steers receiving the barley silage-based diet gained weight faster, at $0.97 \mathrm{~kg} /$ day, than steers receiving the triticale silage-based diet, at $0.88 \mathrm{~kg} / \mathrm{day}$ (Table 4).

There was year-to-year variation with steer receiving the barley silage-based diet in year 2 having ADG (1.05 kg/steer/day) that was $117 \%$ of the ADG that was observed in year $1(0.89 \mathrm{~kg} / \mathrm{steer} /$ day $)$. Steers receiving the triticale silage-based diet in year 2 had ADG $(0.91 \mathrm{~kg} / \mathrm{steer} /$ day $)$ that was $105 \%$ of the ADG observed in year 1 ( $0.86 \mathrm{~kg} / \mathrm{steer} /$ day $)$. Variation between years can be attributed to the combined impacts of variability in cattle, silage quality, and environment, particularly weather and is why year was included as a random blocking factor.

Similar to $D M I$ and $A D G$, for feed efficiency there were no interactions $(P>0.05)$ between diet and the linear or quadratic effects of RFI, no independent linear or quadratic effects $(P>0.05)$ of RFI, and only an effect $(P<0.01)$ of diet $($ Table 3$)$. The lower DMI and greater gain of steers receiving the barley silage-based diet resulted in greater feed efficiency, at 0.16 kg ADG:kg DMI, than occurred for the steers receiving the triticale silage-based diet, at $0.14 \mathrm{~kg} \mathrm{ADG:kg} \mathrm{DMI}$, with their greater DMI and lower ADG (Table 4). Feed conversion (kg DMl:kg ADG; inverse of feed efficiency) was 6.21 and $7.29 \mathrm{~kg}$ DMI:kg ADG for the barley silage- and triticale silage-based diets.

\section{Cost, revenue, profitability of steers, and silage value}

The gross cost of backgrounding steers was not affected $(P>0.05)$ by any interactions between diet and the linear or quadratic effects, or any independent linear or quadratic effects of cattle efficiency type as assessed by observed pen average RFI (Table 3). There was an effect $(P<0.01)$ of diet on gross cost $($ Table 3$)$ with steers receiving the barley silage-based diet 
having a 112-day gross cost of $\$ 263 /$ steer vs. $\$ 276 /$ steer for steers on the triticale silage-based diet (Table 4$)$. The average cost for steers on triticale silage was $5 \%$ higher than the cost on a barley diet. Feed costs were $62.2 \%$ of total costs for steers fed the barley silage-based diet. Silage cost was $\$ 80$ or $30.5 \%$ of the total cost, cDDGS-based supplements $\$ 83$ or $31.7 \%$, yardage $\$ 68$ or $26 \%$, bedding $\$ 12$ or $4.5 \%$, and other costs $\$ 20$ or $7.3 \%$ of the total cost. Similarly, for steers fed the triticale silage-based diet, feed costs were $63.8 \%$ of total costs. Silage cost was $\$ 86$ or $31.3 \%$ of the total cost ( $\$ 276 /$ steer), cDDGSbased supplements $\$ 90$ or $32.5 \%$, yardage $\$ 68$ or $24.8 \%$, bedding 12 or $4.3 \%$, and other costs $\$ 20$ or $7.1 \%$ of the total cost.

Gross revenue from backgrounding steers was not affected $(P>0.05)$ by any interactions between diet and the linear or quadratic effects, or any independent linear or quadratic effects of observed pen average RFI (Table 3). There was an effect ( $P$ $=0.01$ ) of diet on gross revenue (Table 3 ) with steers receiving the barley silage-based diet generating revenue of $\$ 288 /$ steer vs. $\$ 268 /$ steer for steers on the triticale silage-based diet (Table 4).

For NR, there were no interactions $(P>0.05)$ between diet and the linear or quadratic effects of $\mathrm{RFI}$, or independent quadratic effects $(P>0.05)$ of RFI (Table 3$)$. However, there was an effect $(P<0.01)$ of diet and a linear effect $(P<0.05)$ of RFI on NR (Table 3). There was a negative return of $\$ 7$ for the steers fed the triticale silage-based diet whereas the steers fed the barley silage-based diet had positive return of $\$ 25$. This is a $\$ 32$ difference between the two diets. The slope for regression of NR on observed pen average RFI indicates an improvement of $\$ 30$ in NR for every kg of improvement in RFI (Table 4). With the range in pen average RFI observed in this study $(0.86 \mathrm{~kg}$; data not shown) or + 1 SD vs -1 SD ( $0.50 \mathrm{~kg}$; data not shown), this equates to an improvement in NR of $\$ 26 /$ steer or $\$ 15 /$ steer, respectively. There was year-to-year variation apparent for NR with steers fed the barley silage-based diet generating $\$ 40 /$ steer in year 2 compared to $\$ 9 /$ steer in year 1 . Similarly, NR for steers fed the triticale silage-based diet was $-\$ 1 /$ steer in year 2 compared to $-\$ 13 /$ steer in year 1 .

The values for barley or triticale silages were calculated both at actual DM content and at the industry standard 35\% DM content. When calculated at actual DM, there were no interactions $(P>0.05)$ between diet and the linear or quadratic effects of observed pen average RFI, and no effect $(P>0.05)$ of diet or independent quadratic effect of observed pen average RFI (Table 3). There was a linear effect $(P=0.03$; Table 3) for observed pen average RFI where each $\mathrm{kg}$ improvement (reduction) in $\mathrm{RFI}$ resulted in an increase in the breakeven value of silage of $\$ 22$ per tonne (Table 4). With the range in pen average RFI observed in this study $(0.86 \mathrm{~kg}$; data not shown) or +1 SD vs. -1 SD $(0.50 \mathrm{~kg}$; data not shown), this equates to an improvement in value of silage at actual DM content of $\$ 19 /$ tonne or $\$ 11 /$ tonne, respectively. The average breakeven value for barley silage at actual DM was $\$ 68 /$ tonne (Table 4 ), $132 \%$ of the assumed market price (\$52/tonne; Table 2 average) of barley silage used in determination of NR. For triticale silage, the breakeven value at actual DM (\$61/tonne; Table 4) was $92 \%$ of the $\$ 67 /$ tonne value (Table 2 average) used in determination of NR.

When the breakeven value of silage was determined at a standardized 35\% DM, there was no interaction $(P>0.05)$ between diet and the linear or quadratic, or independent quadratic effects of observed pen average RFI (Table 3). There was an effect of diet $(P<0.01)$ and a linear effect $(P=0.03)$ of observed pen average RFI (Table 3). When standardized to 35\% DM, the breakeven value of silage for steers fed the barley silage-based diet, at $\$ 74 /$ tonne, was greater than for triticale silage when fed to steers on the triticale silage-based diet, at $\$ 52 /$ tonne (Table 4). These breakeven values for barley silage and triticale silage are $130 \%$ and $92 \%$, respectively of the silage price suggested through industry standard pricing methods [37]. The linear effect of observed pen average RFI on the breakeven value of silage when standardized to $35 \% \mathrm{DM}$ was $-\$ 20$, indicating greater silage value when fed to more efficient cattle types. With the range in pen average RFI observed in this study $(0.86 \mathrm{~kg}$; data not shown) or + 1 SD vs. -1 SD ( $0.50 \mathrm{~kg}$; data not shown), this equates to an improvement in value of silage at $35 \% \mathrm{DM}$ content of $\$ 17 /$ tonne or $\$ 10 /$ tonne, respectively.

\section{CO2 equivalent $\mathrm{CH} 4$ emissions}

There was no $(P>0.05)$ diet by observed pen average RFI linear or quadratic interactions, or independent linear or quadratic effect of observed pen average RFI for predicted $\mathrm{CH}_{4}$ emissions on $\mathrm{kg} / \mathrm{steer} / \mathrm{day}$, $\mathrm{kg} / \mathrm{kg}$ DMI, $\mathrm{kg} / \mathrm{kg}$ ADG basis (Table 3). There was an effect $(P<0.01)$ of diet on $\mathrm{CH}_{4}$ emissions when expressed on $\mathrm{kg} / \mathrm{steer} / \mathrm{day}$, or $\mathrm{kg} / \mathrm{kg} \mathrm{ADG}$ basis, but not $(P>0.05)$ on a $\mathrm{kg} / \mathrm{kg}$ DMI basis. The predicted $\mathrm{CH}_{4}$ emissions, in $\mathrm{CO}_{2} \mathrm{e}$ units, were lower for steers fed the barley silage-based diet, at 3.09

Page $11 / 24$ 
$\mathrm{kg} / \mathrm{steer} /$ day and $3.23 \mathrm{~kg} / \mathrm{kg} \mathrm{ADG}$, than for steers fed the triticale silage-based diet, at $3.35 \mathrm{~kg} / \mathrm{steer} / \mathrm{day}$ and $3.81 \mathrm{~kg} / \mathrm{kg} \mathrm{ADG}$ (Table 4).

The NR per unit of $\mathrm{CH}_{4}$ emissions, on a $\mathrm{CO}_{2}$ e basis, was also not affected $(\mathrm{P}>0.05)$ by observed pen average RFI linear or quadratic interactions, or independent quadratic effect of observed pen average RFI (Table 3). There was an effect of both diet $(P<0.01)$ and a linear effect $(P=0.03)$ of observed pen average RFI. Steers fed the barley-silage based diet had greater NR, at $\$ 8 / \mathrm{kg} \mathrm{CO}_{2} \mathrm{e}$, than steers fed the triticale silage diet, at $-\$ 2 / \mathrm{kg} \mathrm{CO}_{2} \mathrm{e}$ (Table 4). The slope of $-\$ 9 \mathrm{NR} / \mathrm{kg} \mathrm{CO}$ e per $\mathrm{kg}$ of observed pen average $\mathrm{RFI}$ indicates greater revenue per unit of $\mathrm{CH}_{4}$ emissions with more efficient cattle types. With the range in pen average RFI observed in this study ( $0.86 \mathrm{~kg}$; data not shown) or + $1 \mathrm{SD}$ vs. $-1 \mathrm{SD}(0.50 \mathrm{~kg}$; data not shown), this equates to an improvement in $\mathrm{NR}$ of $\$ 8 / \mathrm{kg} \mathrm{CO} 2 \mathrm{e}$ or $\$ 5 / \mathrm{kg} \mathrm{CO} 2 \mathrm{e}$, respectively.

When $\mathrm{CH}_{4}$ emissions were estimated under the hypothetical scenario of steers receiving a un-supplemented (silage-only) diet and factorial effects of supplementation and silage type assessed, there were silage type by supplementation interactions $(P<$ 0.01) for emissions on a kg/steer/day, kg/kg DMl, and kg/kg ADG basis (Table 5). Simulations that excluded the cDDGSbased supplement increased $(\mathrm{P}<0.01)$ expected emissions on a $\mathrm{kg}$ of $\mathrm{CO}_{2} \mathrm{e} / \mathrm{steer} /$ day basis for the barley silage diets, but decreased $(P<0.01)$ emissions on the same basis when cDDGS based supplements were removed from the triticale silage diets (Table 5). The lower $(P<0.01) \mathrm{kg} / \mathrm{steer} /$ day emissions estimates from observed performance for barley silage-based vs. triticale silage-based diets were noted earlier, and were negated $(P=0.07)$ when comparisons were made between barley silage-only (at $3.19 \mathrm{~kg} \mathrm{CO} 2 \mathrm{e} /$ steed/day) and triticale silage-only (at $3.29 \mathrm{~kg} \mathrm{CO}{ }_{2} \mathrm{e} / \mathrm{steed} /$ day) simulated diets (Table 5). Comparisons on a kg/kg DMI basis only found effects for comparisons of barley silage-based vs barley silage-only $(P<0.01)$ and triticale silage-based vs triticale silage-only diets $(P=0.03)$. On a $\mathrm{kg}$ of $\mathrm{CO}_{2} \mathrm{e} / \mathrm{kg} \mathrm{ADG}$, all simple effect methane emissions comparisons differed $(\mathrm{P}<0.01)$ and the increase in estimated $\mathrm{kg}$ of $\mathrm{CO}_{2} \mathrm{e} / \mathrm{kg} \mathrm{ADG}$ that occurred with switching from barley silage-only to triticale silage-only diets was $224 \%$ of the difference estimated previously when switching from barley silagebased to triticale silage-based diets.

Table 5

Actual silage-based diet and simulated silage only methane emissions means.

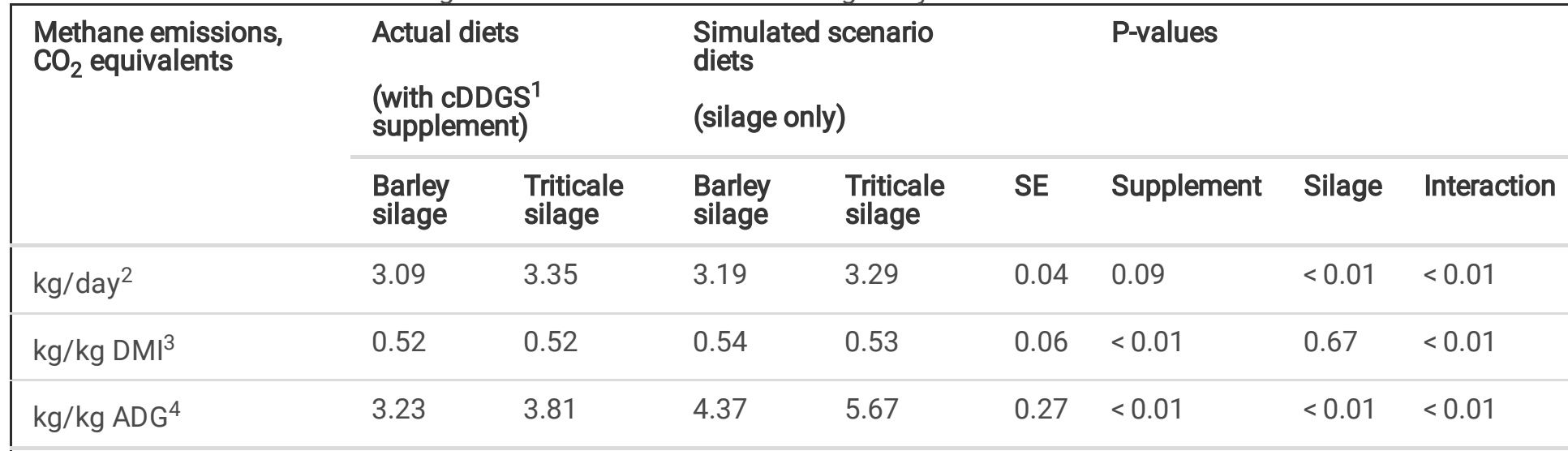

${ }^{1}$ cDDGS, corn dried distillers grains

${ }^{2}$ All simple effect mean comparisons are different $(P<0.01)$ except barley silage-only vs triticale silage-only $(P=0.07)$

${ }^{3} \mathrm{DMl}$, dry matter intake. Barley silage-based diet differs $(\mathrm{P}<0.01)$ from barley silage-only, triticale silage-based diet differs $(P=0.03)$ from triticale silage-only, barley silage-based diet does not differ $(P=0.45)$ from the triticale silage-based diet, barley silage-only diet does not differ $(P=0.12)$ from the triticale silage-only diet

${ }^{4} A D G$, average daily gain. All simple effect comparisons are different $(P<0.01)$ 
The two-sample Hotelling T2 test result $(P=0.9999)$ found no difference between the mean and variances of the observed steer weights from the feeding trial and the mean and variances of the steer weights used in the simulation model (Supplemental Table 1). Similarly, there was no difference $(P=0.9999)$ between the mean and variation of the historical and simulated steer prices.

The CDF constructed from simulated steer weight and steer prices showed a preference dominance for treatments. From most to least preferred over most of the range in NR values, the treatment order was efficient steers on barley silage-based diet, inefficient steers on barley silage-based diet, efficient steers on triticale silage-based diets, then inefficient steers on triticale silage-based diets. Treatments converged at e extreme expected NR values and there was some crossover between efficient and inefficient steer types on the barley silage-based diet at low expected NR (Fig. 1). Use of a negative exponential utility function with the SERF approach (Fig. 2) maintained the same treatment ranking with efficient steers on barley silage-based diet being the most risk efficient diet with higher CE across all levels of risk aversion. A risk-neutral producer $(A R A C=0)$ with efficient steers would require a $\$ 32 /$ steer premium to chose the triticale silage-based diet over the barley silage-based diet. For the same risk neutral producer, the compensation required to choose triticale silage-based diets over barley silage-based diets increases to $\$ 43 /$ steer with inefficient steers. A risk neutral producer would value efficient steers on the barley silage-based diet were worth $\$ 13 /$ steer more than inefficient steers. The value of efficient steers over inefficient steers to a risk neutral producer was $\$ 24 /$ steer when a triticale silage-based diet is fed. Counter intuitively, there was convergence of treatment preferences as producer risk aversion increased with lower compensation required to encourage more risk adverse producers to switch from barley silage-based diets to triticale silage-based diets or from efficient to inefficient steers. This analysis is based on a RFI difference between efficient and inefficient cattle types of $0.45 \mathrm{~kg} /$ day for steers on the barley silage-based diet and 0.48 $\mathrm{kg} /$ day for steers on the triticale silage-based diet. It does not account for any cost incurred in determining the cattle efficiency type or any agronomic differences in cost of production or yield potential in the production of barley or triticale silages.

\section{Discussion}

\section{Adequacy of RFI predictions}

The lack of agreement between the predicted pen average RFI values used in assigning cattle efficiency quartiles when randomizing steers to pens and the observed pen average RFI values based on observed intake, weight, gain, and final ultrasound backfat was due predominately to a lack of precision with the genomic based estimates of RFI. By definition, the average observed RFI for a contemporary group, all pens steers in a given year of backgrounding for our study, is zero and was very close to the average predicted RFI in year $1(0.016 \mathrm{~kg})$ and year $2(0.014 \mathrm{~kg})$. The stated accuracy for individual steer RFI molecular breeding values averaged 0.35 in year 1 and 0.37 in year 2 . Testing for interactions between cattle efficiency type as defined by RFI and diet quality as represented by diets based on two different types of silage using imprecise estimates of RFI is not sensible. This was the reason why our analyses approach changed from a planned 2 (diet) by 4 (cattle efficiency type as defined by RFI) factorial to a 2 (diet) by linear or quadratic cattle efficiency type (defined as observed pen average RFI) factorial.

Conventional RFI testing of beef cattle cannot start before weaning and typically requires an evaluation period in excess of two to three months after a diet adaptation phase [50,51]. This effectively prevents the cattle efficiency type (RFI status) of cattle from being measured in advance of the start of the backgrounding period, and in the case of interaction between cattle efficiency type and management (i.e. diet), limits the ability to optimize beef production by matching cattle efficiency types to different management systems. The intention behind our use of genomic testing to allocate weaned calves to cattle efficiency type groups based on predicted RFI was to be able to access and use this information before it could be obtained from conventional assessment methods. Although prediction imprecision with this approach was shown to be ineffective for the current study, future developments in use of genomic tools to identify difference in cattle efficiency type may be sufficiently improved to allow optimization of beef production by allocation of cattle to various management systems based on cattle efficiency type.

\section{Steer performance}

Page $13 / 24$ 
The objective of this study focuses on the effects and interactions of cattle efficiency type and diet on the economics and estimated $\mathrm{CH}_{4}$ emissions for backgrounding steers. With DMI being a major determinant of production cost and $\mathrm{CH}_{4}$ emissions, ADG affecting gross revenue, and feed efficiency affecting profitability, these aspects of steer performance are important to review in regard to their contributions to the economic and $\mathrm{CH}_{4}$ emissions efficiency of backgrounding steers.

The greater DMI by steers on the triticale silage-based diets than the steers on the barley silage-based diets was not expected. Generally, increased diet energy (digestible, metabolizable, or net energy) content is expected to result in increased voluntary DMI until relatively high diet energy levels are reached [26]. The barley silage had higher energy content than the triticale silage (data not shown) and diets based on both silages received the same cDDGS based supplement at the same inclusion level. Even with the increase in diet energy content from the cDDGS based supplement, neither diet had enough energy that diet energy content was expected to start limiting DMI. A comparable study [52] fed barley and triticale silage-based diets to weaned heifer calves and observed DMI by heifers fed the triticale silage-based diet that was $80 \%$ of the DMI of heifers fed barley silage-based diets, in keeping with conventional expectations related to apparent silage quality. McCartney and Vaage [52] also fed the same barley silage and triticale silage to sheep in a digestibility trial and observed DMI by sheep fed the triticale silage to be $58 \%$ of the DMI by the sheep fed the barley silage. It is probable that the magnitude of DMI difference between the two trials is due to selectivity difference between cattle and sheep, but it is also possible that providing a greater level of supplementation with the cattle trial mitigated the effect of silage quality on DMI. Their diets used different cultivars of barley and triticale, generally lower quality silage with greater quality difference between silages, and a barley grain-based supplement fed at a lower proportion of total DMI than the CDDGS based supplement used with diets in our study. Our unexpected observation of greater DMI by steers fed triticale silage-based diets than steers fed barley silage-based diets could be due to differences in silage cultivars, generally higher silage quality with less difference between silage types, higher supplementation levels and use of a cDDGS-based supplement formulated to address an expected metabolizable protein deficiency instead of barley grain-based supplement. In contrast, to our observations and the findings of McCartney and Vaage [52], Kennedy et al. [53] compared grass silage, lupin/triticale silage, vetch/barley silage, and blends of grass silage with the other two silages and found no differences in DMI due to silage type.

As a measure of cattle efficiency type that is independent of production [6, 7], RFI is moderately heritable and repeatable [51]. Cases where normal expectations of RFI effect have not been observed include those in which diet has been changed, DMI may have been limited by feed factors, or where direct measurement is difficult (i.e. pasture)[51]. Failure to observe a relationship between cattle efficiency type and DMI with our study may be attributed to use of pen-based instead of individual animal observation, allocation of animals to pens based on what was later deemed to be imprecise estimates on RFI, and how the central limit theorem would reduce the relative range in RFI values. A lower range in cattle efficiency type values would make detection of any relationship between $\mathrm{RFI}$ and $\mathrm{DMI}$ more difficult. Our range in RFI molecular breeding value estimates for individual steers was $0.58 \mathrm{~kg}$ in year 1 and $0.50 \mathrm{~kg}$ in year 2 . For pens of steers the range in RFI molecular breeding values was reduced by ca. $50 \%$ to 0.30 in year 1 and 0.27 in year 2 . Similar impact would be expected with DMI of pens of steers showing lower range than DMI of individual steers. Following ca. two generations of selection for divergent RFI, the difference in mean RFI between high and low selection lines was $1.25 \mathrm{~kg}$ [7]. The adjusted R2 for our prediction of standardized DMI was 0.49 and compares to a multi-study average of 0.70 for individual cattle [51].

The overall ADG of steers in the study was typical of backgrounding cattle. Observation of greater gain by steers fed the barley silage-based diet than steers fed the triticale silage-based diet was as expected. The barley silage used was higher quality than the triticale silage (data not shown) and the same cDDGS-based supplement was used in both diets at the same inclusion level. This observation is comparable to that of McCartney and Vaage [52] who found ADG for heifers was greater with barley silage-based diets $(0.65 \mathrm{~kg} /$ day $)$ than with triticale silage-based diets $(0.49 \mathrm{~kg} /$ day). The smaller difference between silagebased diets in the current study vs. the study by McCartney and Vaage [52] can be attributed to the greater intake of the triticale silage-based diet in the current study partially compensating for the lower quality of the silage. Kennedy et al. [53] did not observe any differences in ADG of steers fed lupin/triticale or vetch/barley silages, with or without inclusion of grass silage. The lack of effect of cattle efficiency type, as based on observed pen average RFI, is entirely attributable to the use of pen average ADG in the determination of RFI and is why the P-value for the effect of RFI on ADG is 1.00.

Page $14 / 24$ 
With diet being the only factor affecting DMI and ADG of steers, it is not surprising that the feed efficiency of steers was also affected only by diet. Characterization of cattle efficiency type using observed pen average RFI meant that cattle efficiency type was already adjusted for differences in in cattle size, ADG, and composition of gain before comparing against feed efficiency. The lower DMI and greater ADG of steers fed the barley silage-based diets combined to result in better feed efficiency than the steers fed the triticale silage diets. Although greater DMI with the triticale silage-based diet was unexpected, greater ADG and better feed efficiency with the barley silage-based diet were expected given the better quality of the barley silage and the resulting diet. McCartney and Vaage [52] presented feed conversion instead of the more appropriate feed efficiency and found triticale silage-based diets, at $109 \%$ of barley silage-based diet, not to differ from barley silage-based diets. The reciprocals of the feed conversion values reported McCartney and Vaage [52] indicate feed efficiency values that ca. $60 \%$ poorer than observed in the current study. Reasons for better feed efficiency than reported previously include a higher inclusion level of a cDDGS-based supplement formulated to address an expected metabolizable protein deficiency and support efficient lean gain, but also supplying more energy than a barley grain-based supplement, and use of steers with more lean growth potential than heifers. Most of these same reasons also apply when comparing the current study findings to the observations of Lopez-Campos et al. [54]. The feed efficiency observed in the current study approached levels more commonly expected for feedlot cattle receiving a high-grain finishing diet [8]. Explanation for this high level of feed efficiency on a foragebased diet include the high quality of the silages used, the increase in diet energy level that resulted from use of a cDDGSbased supplement to increase metabolizable protein supply while still limiting the risk of ruminal acidosis, the efficiency of gain when the production objective is to maximize lean growth with minimal fattening, and the favourable winter feeding environment where cattle were sheltered from wind and freezing weather prevented issues with mud

\section{Cost, revenue, profitability of steers, and silage value}

Overall, feed cost was $62.2 \%$ of the total cost for barley silage/corn supplements and $63.8 \%$ for triticale silage/corn supplements. Greater feed cost for the steers fed the triticale silage-based diets are attributed to the greater DMI of these steers as the unit cost of silage and supplement was the same for both diets. Randomization of steers to pens to equalize initial weight and weight distribution resulted in equal steer purchase prices. The remainder production costs for backgrounding, including bedding, yardage, marketing and transport costs, were also equal across treatments. A survey of beef producers in Alberta showed that feeding and management through the winter comprise up to two-thirds of the total cost of primary beef production [3]. A guideline developed by Manitoba Agriculture for backgrounding cattle production [55] has shown that feed costs comprise about $61 \%$ of the operating costs of backgrounding commercial cattle production. Generally, feed costs amount to $61 \%$ of total costs for a typical backgrounding operation [56]. This supports our observed cost distribution as being representative of industry practice.

The greater gross revenue for steers fed the barley silage-based diet is due to the greater ADG for these steers in response to the greater quality of the barley silage vs the triticale silage. Decreasing unit prices with increasing weight is a normal situation with cattle markets, and partially offsets the greater value of larger cattle in response to larger cattle having lower potential for additional profit before reaching slaughter weight. Large price discounts associated with excess size for slaughter cattle are not common with backgrounding cattle. Increased steer weight at the end of the backgrounding period in the current study increased gross revenue.

Lower feed costs, similar other production costs, and greater gross revenue for steers fed the barley silage-based diet combined to result in greater net revenue than observed with steers fed the triticale silage-based diet. Improved performance of cattle resulting from feeding better quality diets of similar cost should improve economic returns from cattle production. Negative net returns for the steers fed the triticale silage-based diets are not unexpected. Profit margin for a backgrounding operation in western Canada is about $\$ 30 /$ steer not including risk management cost [56]. Profit margin could go to negative $\$ 24 /$ steer if risk management cost for backgrounding operation is included. Various industry-based assessments of backgrounding profitability indicate negative returns from backgrounding. Return on investment and return on asset for a typical backgrounding operation in Manitoba were estimated to be negative 2.2\% and $7.7 \%$, respectively [55]. Backgrounding systems decisions have implications for other beef production segments and are often focused on minimizing costs. Our

Page $15 / 24$ 
finding of marginal or positive returns in this study suggest an opportunity for improved economic performance from backgrounding as a result of increased attention to diet quality and animal performance.

Despite lack of effect on DMI, ADG, feed efficiency, gross cost, or gross revenue, more efficient cattle types, based on observed pen average $\mathrm{RFI}$, were also more profitable. With RFI identifying cattle with lower feed intake, given weight, ADG, and composition of gain, more efficient cattle types are expected be more profitable. It is unfortunate that the lack of precision observed for genomic prediction of RFI prevented identification of this value difference in cattle type prior to the start of the feeding trial. Post-trial pen average RFI did confirm economic value for more efficient cattle types that only requires improvement in early prediction for beef producers to be able to benefit from. Dividing the pens of steers into efficient $(\mathrm{RFI}<0)$ and inefficient $(\mathrm{RFI}>0)$ groups would have resulted in the efficient pens of steers having a \$12 NR advantage. This compares to the $\$ 32$ observed benefit to NR from difference in diet quality which was 2.68 times the benefit from feed efficiency.

Silages are rarely traded feeds making price discovery difficult. A common approach to price determination is base silage value on a conversion from alternate crop uses. Barley crops grown for silage could be allowed to mature and be harvested for feed grain, for which there is a substantial market and sound price reporting. Barley silage value is estimated as 12.5 times the bushel price of feed barley [37]. A similar approach has not been established for triticale silage. An alternative for value determination would be to calculate silage value based on operation breakeven and known costs for all other activities. Assuming all other prices and costs are known except the price and cost of silage, a breakeven value $(\mathrm{NR}=0)$ was calculated for the barley silage and triticale silage as used in the current study. This approach integrates management consideration into silage value and would reflect a market reality that differences in management can affect silage value. Silage costs above these breakeven values would not be acceptable and prices below these values would represent increased opportunity for profit. Our study findings indicated the higher quality of barley silage supports a higher valuation than the currently assumed industry price. Alternatively, triticale silage valuation was below the currently assumed industry price. This difference between silages required that prices be expressed at a standard 35\% DM and is consistent with the differences in profitability expected for the two different silage-based diets. Lack of difference at actual DM just indicates that the difference in silage DM content compensated for the difference in silage value. Silage value also increased with more efficient cattle types indicating the returns expected for each silage would increase when the silage was used more effectively by the steers. Our evaluation does not address agronomic considerations in silage production in relation to silage yields or silage cost of production. It is possible that agronomic considerations could alter silage preference for backgrounding relative to just steer economic based preferences.

\section{CO2 equivalent $\mathrm{CH} 4$ emissions}

The scope of the current study did not include direct measurement of $\mathrm{CH}_{4}$ emissions from backgrounding steers. An assessment of emissions is an item of increasing importance with growing awareness and attention to the role of greenhouse gas emissions in climate change. The $\mathrm{CH}_{4}$ from all enteric fermentation represents just over $3 \%$ of all Canadian greenhouse gas emissions [57]. Relative to cow-calf and feedlot segments of beef production, the smaller size of backgrounding cattle and shorter duration of the backgrounding phase result in a reduced contribution to these emissions. However, public perception can be out of proportion to the magnitude of emissions. Addressing emissions concerns may have important implications for market competitiveness and consideration with carbon tax and credit systems. For the current study, the NASEM [26] model was used to predict $\mathrm{CH}_{4}$ emissions for each pen of steers based on observed ingredient nutrient contents, diet compositions, steer weights and ADG, and DMI. This model several different approaches to estimate $\mathrm{CH}_{4}$ emissions and then reports a median estimate, which is what was used for the current study. This approach has the advantage of being able to assess $\mathrm{CH}_{4}$ emissions related impacts of cattle management options at relatively low cost but the disadvantage of dependence on predictive model accuracy and precision.

The observation of lower estimate $\mathrm{CH}_{4}$ emissions for steers fed the barley silage-based diet on a per steer/day basis but not on a per $\mathrm{kg}$ DMI basis indicates the main driver of difference in estimated $\mathrm{CH}_{4}$ emissions was the greater DMI of steers fed the triticale silage-based diet. Comparably, greater ADG for the steers fed the barley silage-based diet and similar $\mathrm{CH}_{4}$ emissions 
per steer/day resulted lower emissions per unit ADG than for steers fed the triticale silage-based diet. Differences in diet quality were not sufficient to affect $\mathrm{CH}_{4}$ emissions estimates outside of the impact on DMI and ADG. Similarly, with cattle efficiency type having no effect on DMI or ADG, there was no impact of observed pen average $\mathrm{RFI}$ on $\mathrm{CH}_{4}$ emissions on a per steer/day, a per kg DMl, or per kg ADG basis. The impact of diet and cattle efficiency type on the NR per unit emissions indicate that both the barley silage-based diet and the lower observed pen average RFI cattle have a measure of revenue that could be used to offset economic pressure to reduce $\mathrm{CH}_{4}$ emissions. This was not the case for steers fed the triticale silagebased diet, or for pens of steers with lower observed pen average RFI.

For the hypothetical situation of feeding silage-only diets instead of the silage-based diets used in the current study, the adjustments to voluntary intake and energy efficiency relative to NASEM [26] model defaults that were needed to get agreement between observed and predicted DMI and ADG of steers were noted for each pen of steers. These same adjustments were then applied to the silage-only predictions and expected DMI, ADG (as limited by energy, not protein), and $\mathrm{CH}_{4}$ emissions recorded. In all cases of $\mathrm{CH}_{4}$ emissions per steer/day, per unit DMI, or per unit $\mathrm{ADG}$, there were interactions between silage type and the inclusion or removal of the cDDGS-based supplement although the nature of the interactions differed.

On a per steer/day basis, removing cDDGS-based supplement increased expected emissions for steers fed barley silage, reduced emissions for steers fed triticale silage, and eliminated the difference between the barley and triticale silages. On a per $\mathrm{kg}$ DMI basis, removing the cDDGS-based supplement increased emissions estimates and had no impact on comparisons between silages. The increase in $\mathrm{CH}_{4}$ emissions on a per $\mathrm{kg}$ DMI basis after eliminating the cDDGS-based supplement was consistent with expectations from a decrease in diet quality. For barley silage the change on a per kg DMI basis was very similar in magnitude to the change observed on a per steer/day basis indicating most of the impact on a per steer/day basis was due to expected $\mathrm{CH}_{4}$ yield per unit of DMI. With triticale silage, the change on a per $\mathrm{kg} \mathrm{DMI}$ basis was very opposite to the change observed on a per steer/day basis indicating most of the impact on a per steer/day basis was due to reduction in expected DMI. The most profound impact was for $\mathrm{CH}_{4}$ emissions on a per kg ADG basis. Eliminating cDDGS-based supplement substantially reduced expected ADG, more so for triticale silage than barley silage, and resulted in much higher predicted emissions rates. This was based on energy limited estimates of ADG and not the more restrictive protein limited estimates of ADG. Supplementation to address nutrient imbalances was predicted to substantial improve the efficiency of beef production on $\mathrm{CH}_{4}$ emissions basis. Impact of cattle efficiency type was not considered in these comparisons as, apart from using observed performance, the NASEM [26] models have no mechanism to account for differences in cattle efficiency type as related to $\mathrm{RFI}$.

\section{Beef diet ranking: the SERF approach}

Economic analyses expanded beyond focusing just on point estimates, such as treatment means for NR. A risk ranking procedure that does not rely on point estimates or summary statistics is and included the CDF and SERF analysis. A prerequisite for these additional analyses is that the Hotelling $T^{2}$ tests for actual and simulated steer weights and feeder prices were not significant. This was the case and SIMETAR $[43,45]$ was an appropriate method tool to be used to construct CDF from simulated steer weights and feeder prices. The CDF represents all simulated outcomes of NR for all combinations of barley silage-based diets vs triticale silage-based diets and efficient (observed pen average RFI<0) and inefficient (observed pen average RFI >0) treatments. Both CDF and SERF analyses are based on treatment means and variability requiring consideration of cattle efficiency type based on observed pen average RFI as efficient vs inefficient groups instead of as a continuum of observed pen average RFI values. For efficient steers fed barley silage-based diets to be completely dominant alternatives for beef returns would require the efficient steers fed barley silage-based diets to lie on the right-hand side of the CDF curves throughout the entire range of alternative return distributions (Fig. 1). It is apparent that, through most of the CDF range, use of the efficient steers on higher quality barley silage-based diet would be the preferred option for improving net revenues. The NR advantage of efficient steers over inefficient steers fed the barley silage-based diet is generally lower, even reversing at low NR expectations, than the NR advantages observed when the triticale silage-based diet was fed, suggesting the economic premium for efficient cattle type declines with higher quality diets.

Page 17/24 
Since each individual producer may have different risk aversion and differences in risk aversion can affect treatment preferences, additional analyses beyond CDF are necessary to assess the impact of risk aversion on producer preferences. The alternative method of SERF was used to assess the preferred treatment as it is an analytical technique of greater preference because it incorporates risk preference of individual producers $[47,48]$. Similar stochastic variables have been used in previous beef studies $[28,58,59,60,61,62]$. Khakbazan et al. [30, 31] reported a similar SERF analytical technique for ranking different beef management systems.

Figure 2 presents the SERF approach using a negative exponential utility function. This method identifies utility efficient alternatives for a range of risk preferences by ranking alternatives in terms of $\mathrm{CE}[30,31]$. The higher $\mathrm{CE}$ with the same level of ARAC determines the best cattle management alternatives under different individual risk preferences. The CE values repeat the ranking of treatments based on average NR or CDF over most of the CDF range. The convergence in CE with increased risk aversion was unexpected as producer preference for diets and cattle types associated with greater NR would normally be expected to increase with greater risk aversion. An explanation exists in that the treatment combinations with the greatest NR also showed the greatest variation in NR. Variation in NR makes NR less certain and explains why more risk averse producers would have a decrease in preference for the higher NR treatments. Although there was convergence in treatment preference with greater NR, at no point did the ranking of preferred treatments change. Thus, the SERF values results are consistent with other economic findings, strengthening support for selection of efficient steers and use of barley silage-based diets over inefficient steers or triticale silage-based diets by both risk neutral and risk averse beef backgrounders. Difficulty in determining cattle efficiency type in advance of backgrounding, as observed with the results of the current study, makes adoption of differential pricing based on cattle efficiency type challenging. Although strong risk aversion due the typical low margins from backgrounding cattle and converging treatments with increasing risk aversion will reduce preference differences between use of barley silage-based diets and triticale silage-based diets for backgrounding beef steers, there would need to be substantial agronomic considerations for triticale to become preferred over barley for production of silage-based diets for backgrounding steers.

\section{Conclusions}

This study used data collected over two years, 2016/2017 and 2017/2018, to evaluate the economic and $\mathrm{CO}_{2}$ e emission impacts of diet quality and cattle efficiency type on beef production systems. Assessment of RFI prediction adequacy found no relationship between observed RFI and predicted pen average RFI. The barley silage treatments typically provided greater ADG and better feed efficiency, higher NR, and lower $\mathrm{CO}_{2}$ e emission compared to triticale silage treatments. Regression results also showed that NR, but not ADG, was affected by cattle efficiency type. The risk simulation analysis mirrors the findings of the experimental NR results, as producer preferences should be for selection of efficient steers over inefficient steers and barley silage-based diets over triticale silage-based treatments. The difference in certainty equivalent (averaged $\sim 30 /$ steer) of efficient steers on barley silage and inefficient steers on barley silage or efficient or inefficient steers on triticale silage supports a beef backgrounding producer focus on diet quality and cattle efficiency type. However, inefficient steers on barley silage still generated higher certainty equivalent per steer than efficient or inefficient steers on triticale silage. Observed benefit to NR from difference in diet quality was 2.68 times the benefit from cattle efficiency type measured by observed pen average RFI. This study did not address potential agronomic differences, including yield, which could provide nuance to forage choice. To increase understanding and improve assessment of silage diets in relation to profitability, additional models that address agronomic difference between production of barley and triticale silages should be built.

\section{Abbreviations}

ADG: average daily gain; ARAC: absolute risk aversion coefficient; BW: body weight; cDDGS: Corn (Zea mais) dried distillers' grains; CDF: probability distribution function; $C E$ : certainty equivalent; DMl: dry matter intake; gEPD: genomic expected progeny differences; NASEM: National Academies of Sciences, Engineering, and Medicine; NR: net revenue; RFI: residual feed intake; SERF: stochastic efficiency with respect to a function.

Page $18 / 24$ 


\section{Declarations}

\section{Acknowledgements}

The financial support of Agriculture and Agri-Food Canada is gratefully acknowledged. Technical assistance provided by Rebecca Xie is greatly appreciated. The authors thank Michael Vinsky for coordination of SNP genotyping on the animals. We also thank all the researchers, technicians and support staff at the Agriculture and Agri-Food Canada's Lacombe Research and Development Centre in Lacombe, AB.

\section{Authors' contributions}

M.K. and H.B. wrote the manuscript, with input from all authors. H.B. contributed to the research design, project administration, and data collection. J.H. contributed to processing of the data. All authors contributed to the revision of the manuscript. M.K. is responsible for the manuscript as a whole.

\section{Funding}

Agriculture and Agri-Food Canada provided funding for this study.

\section{Availability of data and materials}

The datasets during and/or analyzed during the current study are available from the corresponding authors on reasonable request.

\section{Ethics approval and consent to participate}

All the procedures for this study were conducted in accordance with a protocol approved by the Lacombe Research and Development Centre Animal Care Committee and animals were cared for as outlined under the guidelines established by the Canadian Council on Animal Care [32].

\section{Consent for publication}

Not applicable.

\section{Competing interests}

Agriculture and Agri-Food Canada provided funding for this study. Apart from this, no competing interests need to be declared.

\section{References}

1. Arthur PF, Archer JA, Johnston DJ, Herd RM, Richardson EC, Parnell PF. Genetic and phenotypic variance and covariance components for feed intake, feed efficiency, and other postweaning traits in Angus cattle. J Anim Sci. 2001;79:2805-11.

2. Taylor J, Kerley M, Schnabel R, Pomp D, Garrick D, Hansen SL, et al. National program for genetic improvement of feed efficiency in beef cattle. Faculty Papers and Publications in Animal Science, 907. 2016. https://digitalcommons.unl.edu/animalscifacpub/907. Accessed 27 Jun 2021.

3. Kaliel D, Kotowich J. Economic evaluation of cow wintering systems-provincial swath grazing survey analysis. Alberta Production Economics Branch, Alberta Agriculture, Food and Rural Development, Edmonton, AB, Canada. 2002.

4. Koch RM, Swiger LA, Chambers D, Gregory KE. Efficiency of feed use in beef cattle. J Anim Sci. 1963;22:486-94.

5. Basarab JA, Beauchemin KA, Baron VS, Ominski KH, Guan LL, Miller SP, et al. Reducing GHG emissions through genetic improvement for feed efficiency: Effects on economically important traits and enteric methane production. Animal. 2013;7:303-15. 
6. Herd RM, Bishop SC. Genetic variation in residual feed intake and its association with other production traits in British Hereford cattle. Livest Prod Sci. 2000;63:111-9.

7. Arthur JPF, Herd RM. Residual feed intake in beef cattle. Rev Bras Zootec. 2008;37:269-79.

8. Nkrumah JD, Basarab JA, Price MA, Okine EK, Ammoura A, Guercio S, et al. Different measures of energetic efficiency and their phenotypic relationships with growth, feed intake, and ultrasound and carcass merit in hybrid cattle. J Anim Sci. 2004;82:2451-9.

9. Hoque MA, Suzuki K. Genetics of residual feed intake in cattle and pigs: A review. Asian-Australas J Anim Sci. 2009;22:747-55.

10. Berry DP, Crowley JJ. Cell biology symposium: Genetics of feed efficiency in dairy and beef cattle. J. Anim. Sci. 2013;91:1594-1613.

11. Herd RM, Archer JA, Arthur PF. Reducing the cost of beef production through genetic improvement in residual feed intake: Opportunity and challenges to application. J Anim Sci. 2003;81:E9-17.

12. Bezerra LR, Sarmento JLR, Neto SG, de Paula NRO, Oliveira RL. do Rêgo WMF. Residual feed intake: a nutritional tool for genetic improvement. Trop Anim Health Prod. 2013;45:1649-61.

13. Retallick KM. Evaluation of feedlot feed efficiency relationships as well as genetic and phenotypic performance, carcass, and economic outcomes. PhD Dissertation, University of Illinois, Urbana-Champaign, USA. 2012.

14. Walter J. Effects of residual feed intake classification on feed efficiency, feeding behavior, carcass traits, and net revenue in Angus-based composite steers. Doctoral dissertation, Texas A\&M University. 2012.

15. Basarab JA, Price MA, Aalhus JL, Okine EK, Snelling WM, Lyle KL. Residual feed intake and body composition in young growing cattle. Can J Anim Sci. 2003;83:189-204.

16. Basarab JA, McCartney D, Okine EK, Baron VS. Relationships between progeny residual feed intake and dam productivity traits. Can J Anim Sci. 2007;87:489-502.

17. Jones FM, Phillips FA, Naylor T, Mercer NB. Methane emissions from grazing Angus beef cows selected for divergent residual feed intake. Anim Feed Sci Tech. 2011;166:302-7.

18. Bouquet A, Fouilloux MN, Renand G, Phocas F. Genetic parameters for growth, muscularity, feed efficiency and carcass traits of young beef bulls. Livest Sci. 2010;129:38-48.

19. Arthur PF, Herd RM. Efficiency of feed utilisation by livestock-Implications and benefits of genetic improvement. Can $J$ Anim Sci. 2005;85:281-90.

20. Weaber RL, Beever JE, Freetly HC, Hansen DGS, Johnson KA, Kerley MS, et al. Analysis of US cow-calf producer survey data to assess knowledge, awareness and attitudes related to genetic improvement of feed efficiency. In Proceedings of the 10th World Congress on Genetics Applied to Livestock Production. 2014.

21. Mujibi FDN, Nkrumah JD, Durunna ON, Stothard P, Mah J, Wang Z, et al. Accuracy of genomic breeding values for residual feed intake in crossbred beef cattle. J Anim Sci. 2011;89:3353-61.

22. Bolormaa S, Pryce JE, Kemper K, Savin K, Hayes BJ, Barendse W, et al. Accuracy of prediction of genomic breeding values for residual feed intake and carcass and meat quality traits in Bos taurus, Bos indicus, and composite beef cattle. J Anim Sci. 2013;91:3088-104.

23. Chen L, Schenkel F, Vinsky M, Crews DH Jr, Li C. Accuracy of predicting genomic breeding values for residual feed intake in Angus and Charolais beef cattle. J Anim Sci. 2013;91:4669-78.

24. Khansefid M, Pryce JE, Bolormaa S, Miller SP, Wang Z, Li C, et al. Estimation of genomic breeding values for residual feed intake in a multibreed cattle population. J Anim Sci. 2014;92:3270-83.

25. Hayes BJ, Lewin HA, Goddard ME. The future of livestock breeding: genomic selection for efficiency, reduced emissions intensity, and adaptation. Trends Genet. 2013;29:206-14.

26. National Academies of Sciences. Engineering, and Medicine. Nutrient requirements of beef cattle: Eighth Revised Edition. Washington, DC: The National Academies Press; 2016. https://doi.org/10.17226/19014. 
27. Doce RR, Baron VS, Dick AC. Estimating swath-grazed carrying capacity from plot-scale data. Can J Anim Sci. 2015;95:647-51.

28. Evans JR, Sperow M, D'Souza GE, Rayburn EB. Stochastic simulation of pasture-raised beef production systems and implications for the Appalachian cow-calf sector. J Sustain Agric. 2007;30:27-51.

29. Reisenauer Leesburg VL, Tes MW, Griffith D. Evaluation of calving seasons and marketing strategies in northern great plains beef enterprises: I. Cow-calf systems. J Anim Sci. 2007;85:2314-21.

30. Khakbazan M, Carew R, Scott SL, Chiang P, Block HC, Robins C, et al. Economic analysis and stochastic simulation of alternative beef calving and feeding systems in Western Canada. Can J Anim Sci. 2014;94:299-311.

31. Khakbazan M, Durunna ON, Sirski TK, Brewin DG, Huang J, Berry N, et al. The effects of spring versus summer calving on beef cattle economic performance in western Canada. Can J Anim Sci. 2015;95:475-86.

32. Olfert ED, Cross BM, McWilliam AA. Guide to the care and use of experimental animals. Ottawa: Canadian Council on Animal Care; publication date: 1993, Revision date: April 2020. https://www.ccac.ca/Documents/Standards/Guidelines/Experimental_Animals_Vol1.pdf. Accessed 28 Jun 2021.

33. Ekine-Dzivenu C, Akanno EC, Chen L, McKeown L, Irving B, Baker L, et al. Improvement of cow feed efficiency using molecular breeding values for residual feed intake - The "Kinsella Breeding Project". In Proceedings of the 11th World Congress on Genetics Applied to Livestock Production 11, 809. 2018.

34. Brethour JR. The repeatability and accuracy of ultrasound in measuring backfat of cattle. J Anim Sci. 1992;70:1039-44.

35. Canfax. Alberta Weekly Feeder Prices - Historical weighted average price of feeder steers from 2010 to 2018, provided by Maquis Filion, Agriculture and Agri-Food Canada, Red Meat Section, Ottawa. 2019a.

36. González LA, Schwartzkopf-Genswein KS, Bryan M, Silasi R, Brown F. Factors affecting body weight loss during commercial long haul transport of cattle in North America. J Anim Sci. 2012;90:3630-9.

37. Canfax. Rules of thumb and cattle price relationships. Canfax Research Services Fact Sheet. 2019b.

http://www.canfax.ca/samples/2019\%2009\%20Rules\%20of\%20Thumb\%20and\%20Cattle\%20Price\%20Relationships.pdf. Accessed 28 Jun 2021.

38. Intergovernmental Panel on Climate Change. IPCC's fourth assessment report - Errata. 2012. https://www.ipcc.ch/site/assets/uploads/2018/05/ar4-wg1-errata.pdf. Accessed 26 Jun 2021.

39. Lin LI-K. A concordance correlation coefficient to evaluate reproducibility. Biometrics. 1989;45:255-68.

40. Lin LI-K. A note on the concordance correlation coefficient. Biometrics. 2000;56:324-5.

41. SAS Institute Inc. SAS ${ }^{\circledR} 9.3$ Base SAS. Second Edition ed. SAS Institute Inc., Cary, NC, USA. 2014a.

42. SAS Institute Inc. SAS/STAT ${ }^{\circledR} 13.2$ User's Guide. Cary: SAS Institute Inc.; 2014b.

43. Richardson JW, Schumann K, Feldman P. Simetar@. Simulation and Econometrics to Analyze Risk. Texas: Simetar, Inc. College Station; 2008.

44. Richardson JW, Klose SL, Gray AW. An applied procedure for estimating and simulating multivariate empirical (MVE) probability distributions in farm-level risk assessment and policy analysis. J Agric Appl Econ. 2000;32:299-315.

45. Schumann KD, Feldman PA, Richardson JW. SIMETAR@. Simulation \& econometrics to analyze risk. College Station: Agricultural and Food Policy Center, Texas A\&M University; 2011.

46. Watkins KB, Gealy DR, Anders MM, Mane RU. An economic risk analysis of weed-suppressive rice cultivars in conventional rice production. J Agric Appl Econ. 2018;50:478-502.

47. Hardaker JB, Richardson JW, Lien G, Schumann KD. Stochastic efficiency analysis with risk aversion bounds: a simplified approach. Aust J Agric Resour Econ. 2004;48:253-70.

48. Hardaker JB, Lien G. Stochastic efficiency analysis with risk aversion bounds: a comment. Aust J Agric Resour Econ. 2010;54:379-83.

49. Pratt JW. Risk Aversion in the Small and in the Large. Econometrica. 1964;32:122-36. 
50. Manafiazar G, Basarab JA, McKeown L, Stewart-Smith J, Baron V, MacNeil MD, et al. Optimizing feed intake recording and feed efficiency estimation to increase the rate of genetic gain for feed efficiency in beef cattle. Can J Anim Sci. 2017;97:456-65.

51. Kenny DA, Fitzsimmons C, Waters SM, McGee M. Invited review: improving feed efficiency of beef cattle - the current state of the art and future challenges. Animal. 2018;12:1815-26.

52. McCartney DH, Vaage AS. Comparative yield and feeding value of barley, oat and triticale silages. Can J Anim Sci. 1994;74:91-6.

53. Kennedy PC, Dawson LE, Lively FO, Steen RW, Fearon AM, Moss BW, et al. Effects of offering lupins/triticale and vetch/barley silages alone or in combination with grass silage on animal performance, meat quality and the fatty acid composition of lean meat from beef cattle. J Agric Sci. 2018;156:1005-16.

54. Lopez-Campos O, Aalhus JL, Okine EK, Baron VS, Basarab JA. Effects of calf- and yearling-fed beef production systems and growth promotants on production and profitability. Can J Anim Sci. 2013;93:171-84.

55. Manitoba farm management. Guidelines for estimating beef backgrounding costs. 2020. https://www.gov.mb.ca/agriculture/farm-management/production-economics/cost-of-production.html. Accessed 26 Jun 2021.

56. Canadian Cattlemen. Consider all the costs of backgrounding calves. 2015. https://www.canadiancattlemen.ca/newsroundup/consider-all-the-costs-of-backgrounding-calves. Accessed 27 Jun 2021.

57. Environment and Climate Change Canada. National inventory report 1990-2018: greenhouse gas sources and sinks in Canada. Part 1. 2020. http://publications.gc.ca/collections/collection_2020/eccc/En81-4-2018-1-eng.pdf. Accessed 24 Jun 2021.

58. Schroeder TC, Albright ML, Langemeier MR, Mintert J. Factors affecting cattle feeding profitability. Journal of America Society of Farm Managers Rural Appraisers. 1993;57:48-54.

59. Anderson JD, Lacy C, Forrest CS, Little RD. Expected utility analysis of stocker cattle ownership versus contract grazing in the southeast. J Agric Appl Econ. 2004;36:719-30.

60. Iniguez CR. Assessing the value of two-way information flow in cattle production using stochastic enterprise budgets. M.Sc. thesis, University of Alberta, Edmonton, Alberta, Canada. 2009.

61. Watkins KB, Hignight JA, Beck PA, Anders MM, Hubbell DS III, Gadberry S. An economic risk analysis of stocker grazing on conservation tillage small grains forage in Arkansas. Selected paper prepared for presentation at the Southern Agricultural Economics Association Annual Meeting, Orlando, Florida, February 6-9, 2010.

62. Sirski T. The effect of calving season on economic risk and return in cow-calf operations in western Canada unpublished thesis. M.Sc. thesis, University of Manitoba, Winnipeg, Manitoba, Canada. 2012.

\section{Supplemental Table}

Supplemental Table 1 Summary statistics of simulated steer weights at different diet treatments (kg/steer). B. silage, Barley silage; T. silage, Triticale silage; Q, Predicted RFI quartile; SD, Standard deviation; CV, Coefficient of variation; Min, Minimum; Max, Maximum; Confidence level for two-sample Hotelling $T^{2}$ test was 95\%. Summary statistics calculated from 500 simulated iterations 
Diet Month Simulated steer weight ( $\mathrm{kg} / \mathrm{steer})$
Two-sample (actual data vs simulated data) Hotelling $T^{2}$ test

\begin{tabular}{|c|c|c|c|c|c|c|c|c|}
\hline & Mean & SD & CV & Min & Max & Test value & Critical value & $P$ value \\
\hline Oct. & 284.32 & 34.37 & 12.09 & 182.31 & 377.29 & 0.70 & 23.01 & 0.9999 \\
\hline
\end{tabular}

silage

\begin{tabular}{lllllll}
\hline & Feb. & 392.54 & 39.43 & 10.04 & 290.55 & 485.76 \\
\hline $\begin{array}{l}\text { T. } \\
\text { silage }\end{array}$ & Oct. & 283.35 & 34.90 & 12.32 & 162.39 & 376.33 \\
\hline & Feb. & 382.60 & 37.31 & 9.75 & 276.10 & 489.34
\end{tabular}

Figures

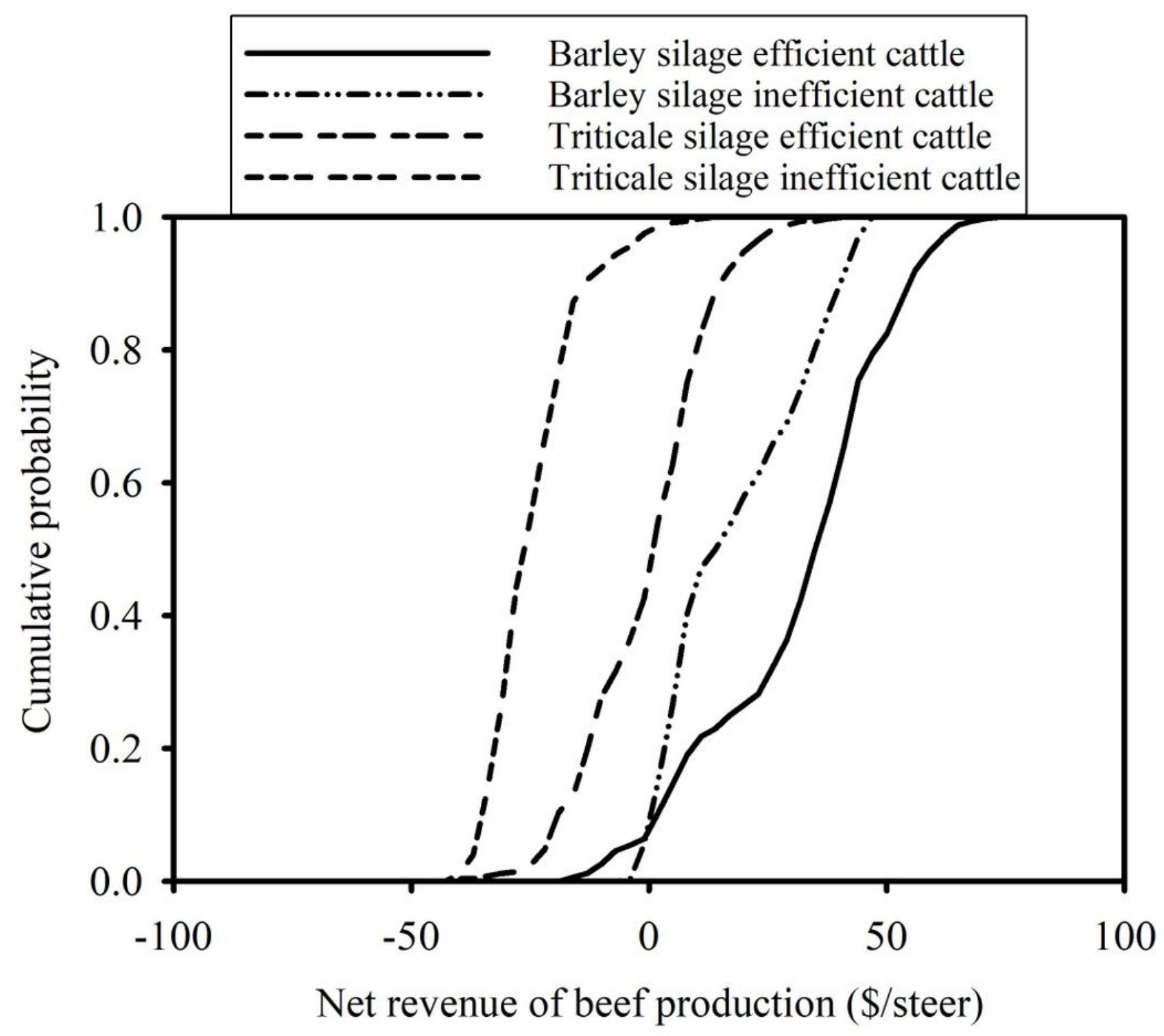

Figure 1 
The cumulative probability of net revenue of barley and triticale silage-based diets and cattle efficiency type in beef backgrounding steers

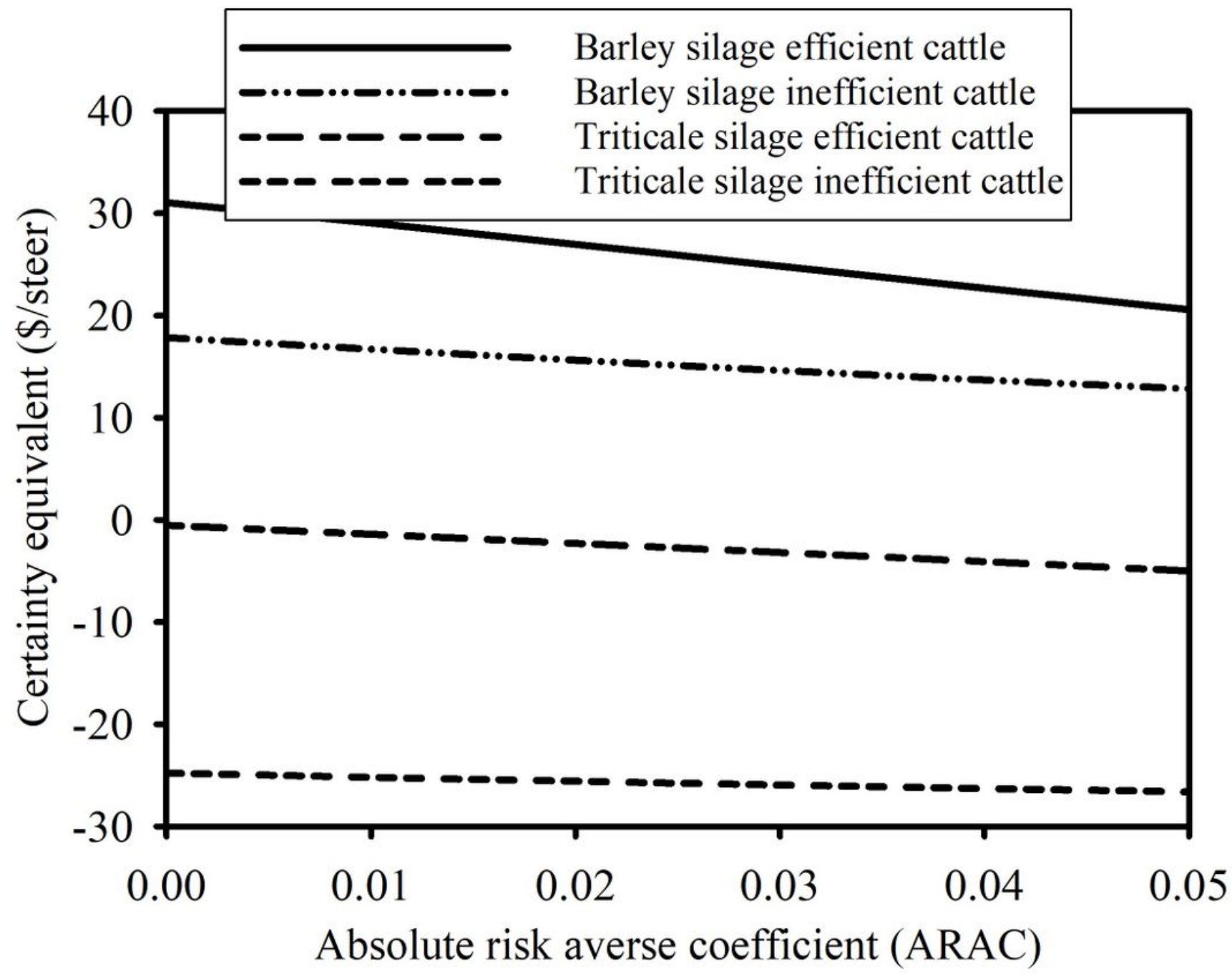

Figure 2

Comparison of certainty equivalent of barley and triticale silage-based diets and cattle efficiency type in beef backgrounding steers 